\title{
Castração química em casos de pedofilia: considerações bioéticas
}

Thais Meirelles de Sousa Maia ${ }^{1}$, Eliane Maria Fleury Seidl ${ }^{2}$

\section{Resumo}

A pedofilia é classificada como doença psiquiátrica e sua prática acaba por atingir e ofender diretamente crianças e pré-adolescentes, sendo um fato social de extrema relevância. O presente trabalho tem como objetivo analisar a eticidade da castração química como mecanismo de controle da pedofilia, problematizando sua eventual tríplice natureza: pena, tratamento médico e experimento científico. Trata-se de um estudo de revisão bibliográfica, mediante o levantamento de literatura especializada sobre bioética, castração química, pedofilia, tratamento médico e ética em pesquisa. Conclui-se que as três acepções não se excluem: a castração química como pena, tratamento médico e experimento científico representa arquétipos que se encontram intrinsecamente ligados, apesar de cada um possuir conotações éticas próprias. Este estudo teve o mérito de ampliar a compreensão do tratamento hormonal para pedófilos, diante da escassez de bibliografia no contexto brasileiro.

Palavras-chave: Bioética. Pedofilia. Psiquiatria.

\section{Resumen}

\section{Castración química en los casos de pedofilia: consideraciones bioéticas}

La pedofilia es clasificada como una enfermedad psiquiátrica y su práctica termina por afectar y ofender directamente a los niños y preadolescentes, al ser un hecho social de extremada relevancia. Este estudio tiene como objetivo analizar la ética de la castración química como un mecanismo de control de la pedofilia, discutiendo su posible triple naturaleza: pena, tratamiento médico y experimento científico. Se trata de una revisión bibliográfica a través de la encuesta de literatura especializada sobre bioética, castración química pedofilia, tratamiento médico y ética en la investigación. Se concluye que los tres significados no son mutuamente excluyentes: la castración química como pena, tratamiento médico y experimento científico, en realidad, son arquetipos que están intrínsecamente vinculados, aunque cada uno tiene sus propias connotaciones éticas. El presente estudio tuvo el mérito de ampliar la comprensión del tratamiento hormonal para los pedófilos, frente a la escasez de bibliografía en el contexto brasileño.

Palabras-clave: Bioética. Pedofilia. Psiquiatría.

\section{Abstract \\ Chemical castration in cases of pedophilia: bioethics considerations}

Pedophilia is classified as a psychiatric disease and its practice ends up directly reaching and offending children and pre-teenagers, being an extreme relevant social issue. This paper aims to analyze the ethics of chemical castration as a tool to avoid pedophilia, problematizing its triple nature: punishment, medical treatment and scientific experiment. It is a bibliographic review, through analyzes of specialized literature on bioethics, chemical castration, pedophilia, medical treatment and ethics in research. It is concluded that the three meanings do not exclude themselves: chemical castration as punishment, medical treatment and scientific experiment are, actually, archetypes which are intrinsically linked, despite each one has their own ethics connotations. This paper had the merit of expanding the hormonal treatment for pedophiles, given the lack of bibliography in the Brazilian context.

Key words: Bioethics. Pedophilia. Psychiatry.

1. Mestre thais_maia@hotmail.com 2. Doutora seidl@unb.br - Universidade de Brasília, Brasília/DF, Brasil.

\section{Correspondência}

Thais Meirelles de Sousa Maia - SQN 314, Bloco J Apt 210 CEP 70767-100. Brasília/DF, Brasil.

Declaram não haver conflito de interesse. 
O presente trabalho tem como objeto de estudo a pedofilia e a castração química como possível solução para controle desse transtorno psiquiátrico, que também vem a ser um crime hediondo, segundo a legislação brasileira. Sendo a pedofilia uma doença reconhecida pela Organização Mundial da Saúde (OMS) e constante da Classificação Internacional de Doenças em sua décima revisão (CID-10) ${ }^{1}$, identificada pelo código F65-4, a mesma é definida como uma preferência sexual por crianças, independentemente do gênero, em idades pré-púberes ou no início da puberdade, sendo adotado como parâmetro a diferença de no mínimo seis anos entre agressor e vítima ${ }^{2}$.

Reconhecida como doença de cunho psiquiátrico, a prática da pedofilia acaba por atingir e ofender diretamente outro ser - no caso, crianças e pré-adolescentes -, sendo um fato social de extrema relevância. Logo, apesar de seu reconhecimento como doença, torna-se pertinente e legítima a interferência estatal para controle da pedofilia, de modo a prevenir futuros abusos por indivíduos que apresentam esse transtorno em sua história de vida. Entretanto, há que se considerar os limites para a atuação do Estado, a autonomia do indivíduo pedófilo, entre outros aspectos de natureza ética que perpassam a matéria.

A castração química, por sua vez, emerge como possível instrumento de controle da doença, considerando que se trata da utilização de substâncias químicas com o intuito de controlar os impulsos sexuais e inibir a libido de indivíduos portadores dessa condição. Sendo assim, trata-se de uma forma de esterilização que atua de modo a inibir a libido e, consequentemente, a prática de relações sexuais. Importante ressaltar que tal procedimento pode acarretar efeitos colaterais relevantes, os quais devem ser levados em conta no momento da decisão quanto à sua eventual adoção ${ }^{3}$. Assim, se por um lado tal conduta é apontada como opção para o controle da pedofilia, por outro, se torna imperiosa a consideração dos demais efeitos advindos da castração química.

Atualmente há três modalidades de aplicação desse procedimento: a castração medicamentosa como pena, de forma a explorar seu caráter punitivo relacionado ao viés criminológico; como tratamento médico que denota a concepção da pedofilia como doença; e por fim, a modalidade de experimento científico, que levanta conflitos referentes à ética em pesquisa. A importância de tal discussão deriva do fato de que a castração química vem sendo aplicada como pena para aqueles julgados pedófi- los em vários países - como Canadá, País de Gales e diversos estados dos Estados Unidos ${ }^{4}$. No Brasil, há projetos de lei no Congresso Nacional tratando do assunto com o mesmo objetivo, o que torna o tema extremamente atual e sua discussão emergencial, dada a necessidade de estabelecer o diálogo ético necessário para que haja um posicionamento técnico-científico e racional acerca da questão.

No âmbito da bioética o tema justifica-se na busca por uma análise ética da castração química destinada a pedófilos, tendo em vista o caráter interventivo do procedimento, de modo que se discute como a castração medicamentosa pode ser encarada sob a perspectiva desse campo de conhecimento: como pena, tratamento médico ou experimento científico. Esse questionamento é transdisciplinar, haja vista que perpassa várias áreas de conhecimento, como a medicina, o direito e a bioética propriamente dita. O tema suscita, ainda, o dilema ético relativo a atuação estatal em face da autonomia, proteção da saúde e liberdade sexual da pessoa submetida à castração química. Ademais, tem-se o debate ético quanto à sua finalidade, tendo em vista que, a depender de sua natureza, diferente será a abordagem da castração medicamentosa nos âmbitos acadêmico, social, médico e subjetivo, ou seja, referente ao próprio indivíduo.

O exame da eticidade da prática da castração química encontra-se presente neste trabalho, sendo oportuno destacar as modalidades de aplicação como tratamento médico e experimento científico, vez que ambos se encontram inseridos no seio da bioética e abordam os possíveis benefícios e riscos do procedimento. Sob o prisma do tratamento são considerados os efeitos colaterais que podem advir ao longo do procedimento e, principalmente, a possibilidade de a castração hormonal ser aplicada como terapia forçada. Com relação ao procedimento da castração medicamentosa como experimento científico foram destacadas as considerações acerca da ética em pesquisa na perspectiva de Mello e Braz ${ }^{5}$, bem como os obstáculos existentes para os sujeitos de pesquisa.

O estudo objetivou analisar a eticidade da castração química como mecanismo de controle da pedofilia, problematizando sua eventual tríplice natureza: pena, tratamento médico e experimento científico. Visou ainda contribuir com o plano bioético de discussões, com o propósito de trazer clareza moral para a problemática. Nessa perspectiva, o trabalho se sustenta em abordagem multifacetada da proposta de aplicação da castração química a pedófilos, do que decorre a complexidade do tema, 
sendo apresentadas as três formas interpretativas identificadas como possíveis sentidos de adoção da castração medicamentosa. Assim, percebe-se a extensa gama de aspectos a serem explorados a partir do assunto em pauta.

\section{Método}

Trata-se de estudo de revisão bibliográfica, realizado mediante o levantamento de literatura especializada sobre "bioética", "castração química", "pedofilia", "tratamento médico", "ética em pesquisa", "autonomia" e "vulnerabilidade". Devido à escassez de trabalhos publicados sobre o tema, foram utilizadas bases de dados diversas, como SciELO, PubMed, Google Scholar e a Biblioteca Virtual em Saúde (BVS), incluindo-se bibliografias estrangeiras. Nessas bases de dados foram explorados os descritores acima mencionados.

A partir do levantamento das referências oriundas de fontes diversas, procedeu-se ao estudo e à seleção daquelas atinentes ao escopo do estudo: selecionaram-se documentos e artigos relevantes para a formação de debate com perspectiva plural. Após a análise do material bibliográfico, a elaboração do artigo foi realizada tendo como ponto de partida a tríplice natureza da castração química. Ademais, cada uma das abordagens foi debatida em face dos conceitos bioéticos da autonomia e da vulnerabilidade.

\section{Castração química}

Antes de aprofundarmos a discussão acerca da tríplice natureza da castração medicamentosa, fazse importante destacar sua conceituação e abrangência. A castração química é um procedimento reversível que se caracteriza pela manipulação de hormônios, conforme explica Ferreira: a castração química é um tratamento terapêutico temporal e completamente reversível mediante o qual se injeta no homem um hormônio sintético feminino - Depoprovera (acetato de medroxiprogesterona/DMPA) - que produz um efeito antiandrógeno que reduz o nível de testosterona para inibir o desejo sexual durante, aproximadamente, seis meses ${ }^{6}$.

Percebe-se que a castração hormonal nada mais é do que um procedimento químico temporal, sendo sua aplicação variável de acordo com cada indivíduo. Embora seja um procedimento reversível, seus efeitos colaterais continuam tendo importância no debate sobre sua adoção. Exemplificando possíveis implicações colaterais resultantes da castração medicamentosa, Ponteli e Sanches Jr. ${ }^{3}$ destacam: doenças cardiovasculares, osteoporose, depressão, dores de cabeça, trombose etc. Percebe-se que tais efeitos adversos afetam o indivíduo tanto na esfera física/biológica como na psicológica/psiquiátrica, o que posiciona a castração medicamentosa como um procedimento não isento de riscos.

Pena

A aplicação da castração química como modalidade de pena a ser imputada pelo Estado ao indivíduo que tenha cometido crime de abuso sexual contra menores é algo que deve ser debatido, haja vista que tal procedimento vem sendo utilizado em vários países. Atualmente, no Brasil, diversas propostas legislativas tratam do tema, propondo a castração química como pena para pedófilos: na Câmara dos Deputados - além de cinco propostas arquivadas tramita o Projeto de Lei 4.399/08 ${ }^{7}$. Já no Senado Federal, enquanto o Projeto de Lei $552 / 07^{8}$ foi arquivado, o PLS 282/11 ${ }^{9}$ está em tramitação.

A justificativa para o uso do procedimento estaria nos altos índices de ocorrência e reincidência de abusos sexuais contra crianças e pré-adolescentes, considerando-se, além disso, o fato de a pedofilia ser uma doença, o que torna necessário o tratamento à diferença dos demais crimes. Neste caso, não há indicação para que o indivíduo seja submetido apenas à pena privativa de liberdade, mas sim que lhe seja ofertado algum tipo de acompanhamento psiquiátrico. Segundo Serafim, um estudo realizado em 2008, publicado na Revista de Psiquiatria Clínica, obteve os seguintes resultados: (...) mais da metade dos criminosos sexuais condenados que acabam de cumprir pena voltam para a penitenciária antes de um ano. Em dois anos esse percentual sobe para $77,9 \%$. A taxa de reincidência varia entre $18 \%$ e $45 \%(\ldots)^{10}$.

As taxas apresentadas no referido estudo apontam que a preocupação de que o pedófilo volte a praticar ato de abuso sexual é fundamentada em dados científicos, devido ao alto índice de reincidência, o que, por seu turno, justifica a busca por meios de controle que garantam a redução de tais números. Portanto, chega-se à conclusão de que o tratamento atual dado ao pedófilo pelo Estado, quando da aplicação da pena privativa de liberdade, é inapropriado e ineficaz, tanto pelo alto número de reincidência quanto pelo fato de que o pedófilo é, 
na verdade, portador de um transtorno psicopatológico.

É importante ressaltar no atual ordenamento jurídico, mesmo resumidamente, que quando o réu de uma ação penal consegue provar que no momento da prática do crime - seja por motivo de doença mental ou desenvolvimento mental incompleto - era incapaz de compreender o caráter ilícito da ação, será isento de pena (art. 26 do Código Penal) ${ }^{11}$. Trata-se de situação que pode ser reconhecida quando da prática de qualquer crime, inclusive nos casos de abuso sexual de menores. Nesses episódios, o réu será submetido à pena de medida de segurança, e não à privação de liberdade, como nos demais casos. É relevante destacar que, segundo Peres ${ }^{12}$, medidas de segurança surgem no Código Penal brasileiro como medidas especiais para criminosos específicos: os doentes mentais perigosos, o que demonstra o tratamento diferenciado que o inimputável e o semi-imputável recebem, fato que, por sua vez, caracteriza a tentativa do ordenamento brasileiro se adequar às necessidades especiais que os indivíduos possam demonstrar.

É nesse contexto que se insere a castração química como pena, posto que se vier realmente a ser aprovada faz-se necessário garantir que seja aplicado o oportuno tratamento àqueles condenados por abuso sexual de crianças e adolescentes, pois - partindo do pressuposto de que se trata de uma doença - é imprescindível que o acusado, uma vez julgado culpado e posteriormente condenado, tenha o acompanhamento e a terapêutica adequados à sua condição, bem como a proteção da sociedade quando de sua liberação.

Ao analisar a castração medicamentosa como pena chega-se à conclusão de que as próprias características da castração - enquanto procedimento médico, químico e psicológico - a diferenciam substancialmente da já conhecida pena restritiva de liberdade, posto que, uma vez prescrita a castração química a ser aplicada ao fim de um processo penal, a mesma deve ser tida como uma forma de tratamento inserido no bojo das medidas de segurança, as quais são voltadas para aqueles considerados inimputáveis ou semi-imputáveis. Assim, percebese que ao se adotar a castração medicamentosa como modalidade de pena, tal natureza se confunde com tratamento médico por excelência, ponto que será explanado posteriormente.

Destarte, os estudos de Stetner e Rodrigues ${ }^{2}$ levam em consideração, justamente, os aspectos concernentes à reinserção na sociedade do indivíduo submetido ao procedimento. A preocupação com sua reintegração social após a submissão à castração medicamentosa é plausível, segundo os autores, vez que também engloba a questão do monitoramento deste indivíduo como forma de observação da evolução do seu quadro, tendo em vista a questão da reincidência. Tais pontos denotam a necessidade de tratamento médico-psiquiátrico e psicológico de responsabilidade, consistindo em uma abordagem completa e não apenas que seja levado em consideração o caráter punitivo da castração química como pena. Assim, percebe-se a dificuldade que o aspecto multifacetado da castração medicamentosa apresenta, pois, ainda que abordada como pena imputada pelo Estado, se confunde com uma modalidade de tratamento - como já asseverado.

Ademais, cumpre ressaltar as considerações de Ponteli e Sanches Jr. ${ }^{3}$ ao afirmarem que a aplicação da castração química seria resultado da busca por uma alternativa à crise dos modelos disciplinares atuais, os quais, representados principalmente pelos presídios, vêm perdendo sua eficácia tendo em vista as superlotações e as condições precárias desses estabelecimentos. Entretanto, pontua-se que apesar de a pena privativa de liberdade executada em penitenciárias realmente não possuir eficácia na busca pela ressocialização do preso, se a castração medicamentosa vier a ser aplicada como penalidade seria executada no âmbito das medidas de segurança, em estabelecimentos voltados para o tratamento dos considerados inimputáveis ou semiimputáveis por algum motivo.

Acredita-se que a crise do sistema penitenciário brasileiro ocorra pelas condições indignas a que são expostos os encarcerados, sendo que tal fato favorece a violência, tanto dentro como fora das penitenciárias. Ainda que os presídios tivessem boa estrutura, essa forma de punição seria ineficaz, haja vista que a pedofilia consiste em uma enfermidade psiquiátrica, conforme mencionado. O fato de a pedofilia ser reconhecida como doença denota a dificuldade de punir o ato, já que também consiste em uma modalidade criminosa. Todas essas peculiaridades corroboram a complexidade em se posicionar com relação ao assunto, posto que o mesmo envolve outras questões que, de alguma forma, encontram-se em pontos opostos, como a autonomia do pedófilo, a proteção da sociedade, entre outros.

Visando melhorar a compreensão acerca do confronto que a adoção da castração química como pena pode vir a ter com os valores de autonomia e de vulnerabilidade da pessoa pedófila, atenta-se novamente para a peculiaridade de que a pedofilia é uma doença psiquiátrica e, uma vez aprovada a 
aplicação da castração medicamentosa como pena, tal procedimento deveria ser adotado como medida de segurança, de forma a proporcionar tratamento compatível e adequado. Contudo, ao se impor uma pena diferente da privação à liberdade, o Estado estaria interferindo também em seus direitos sexuais. Nesse cenário, ao lado da restrição à autonomia pela atuação do Estado (que, no caso de encarceramento, é legítima), há que se considerar a vulnerabilidade do pedófilo perante a situação de uma terapia forçada, aspecto cujas implicações éticas serão mais bem desenvolvidas no próximo tópico. Ressalta-se também a condição especial de vulnerabilidade que o acusado de pedofilia enfrenta no encarceramento pela atuação dos outros encarcerados, cuja violência é tacitamente justificada por uma espécie de 'código de honra' dos presidiários.

Conforme o exposto, percebe-se que a modalidade da castração hormonal enquanto pena é considerada principalmente em seu viés criminológico. Entretanto, essa análise demonstra ser necessário ponderar o pedófilo também a partir de sua doença, de modo a imputar-lhe o tratamento devido, sem, contudo, subsumir sua dívida para com a sociedade decorrente de sua conduta criminosa.

\section{Tratamento médico}

A castração química como tratamento médico implica em um procedimento hormonal para controle da conduta parafílica do sujeito, no caso a pedofilia, sendo que tal doença não possui cura, embora existam mecanismos de controle ${ }^{13}$. Assim, a castração medicamentosa é precipuamente dotada do caráter de tratamento médico, pois a partir do momento em que se compreende o viés patológico da pedofilia percebe-se a necessidade de que sejam ofertados recursos terapêuticos para aqueles indivíduos diagnosticados com tal distúrbio, da mesma forma como deve acontecer com quaisquer outras doenças.

Portanto, ao se tratar da imprescindibilidade de oferta de tratamentos médicos aos cidadãos, esbarra-se na questão atinente ao direito à saúde e ao dever que a prestação deste serviço é para o Estado. Nessa perspectiva, ao se identificar a gravidade e extensão dos danos que a pedofilia provoca na sociedade - para as vítimas e seus familiares e para o próprio pedófilo -, pode-se interpretar a castração química como alternativa terapêutica que se enquadra no desdobramento do direito à saúde, fato que pode suscitar conflitos éticos específicos.
Considerando-se que na presente perspectiva analisa-se a castração química como uma modalidade de tratamento para o indivíduo pedófilo, destaca-se o direito à saúde. A relevância da saúde para a persecução de vida digna de qualquer indivíduo demonstra a pertinência da inclusão do direito à saúde no rol daqueles fundamentais a todos os cidadãos, sendo possível afirmar que uma vida saudável possibilita o exercício de vários outros direitos fundamentais. Desta feita, é cristalina a conclusão de que o responsável pela prestação de tais direitos é o Estado, sendo que no caso da saúde a Constituição de 1988 explicitamente a previu, em seu artigo $196^{14}$, como um dever do Estado.

A saúde, ao mesmo tempo em que se afigura como um direito do cidadão, também se apresenta como dever estatal, ou seja, uma prestação de serviços que deve ser efetivada pelo governo. Ocorre que apesar de se tratar de bem fundamental para que se possa viver dignamente, Sarlet ${ }^{15}$ esclarece que a Constituição Federal não definiu a abrangência desse direito, fato que fragiliza sua efetivação. É neste ponto que residem diversos conflitos tangenciais ao direito à saúde e ao dever de prestação que tal direito representa, concluindo-se pela ineficácia na execução das políticas de saúde, fato que atinge direta e diariamente diversos cidadãos, com as mais variadas doenças e deficiências.

Assim, ao se considerar a castração medicamentosa como possível tratamento para o pedófilo, surge a dúvida de como tal terapêutica seria proposta ao indivíduo, tendo em vista que este é também um criminoso e de seu ato ilícito resulta a violação corporal de um outro ser humano, sendo que nesses casos a vítima é sempre uma criança ou adolescente em idade pré-púbere. Tal situação apenas corrobora o entendimento de que apesar de no presente momento se debater a castração química como forma de tratamento médico, seu viés criminológico não pode ser afastado.

Aqui, entretanto, extrai-se a ideia de que ocorreria uma situação de terapia forçada e amparada por uma prescrição judicial, como explica Hachet ${ }^{16}$. A autora justifica que, de modo geral, no momento em que um indivíduo praticante de um tipo penal é portador de uma enfermidade psiquiátrica, é dever do juiz a prescrição de tratamento para a doença, fato intrinsecamente associado ao direito à saúde. Contudo, já nesse momento estar-se-ia ante um dilema, pois é questionado se o indivíduo deveria ser tratado como criminoso ou paciente. É neste nicho que reside a discussão acerca da castração medicamentosa adotada como tratamento médico. 
Ressalta-se que a posição que se toma face ao conflito pode desencadear outras questões, como, por exemplo, o fato de que o indivíduo como paciente de um tratamento teria resguardado, entre outros direitos, o de escolher o profissional de saúde que o acompanhará. Segundo a autora, uma vez em tratamento, este deveria ser considerado e conduzido como aquele ministrado a um paciente, sendo resguardados todos os direitos que lhe assistem. Entretanto, no caso do indivíduo que cometeu o crime de pedofilia e tem o tratamento legalmente prescrito se estaria diante de uma modalidade forçada de terapia, o que explicita, de forma geral e não apenas no caso da castração medicamentosa, a ambiguidade das medidas de segurança impostas aos condenados com transtornos de ordem psiquiátrica.

Quanto à possibilidade de uma terapia forçada, destaca-se a Lei 10.016 de 2001, que trata dos direitos das pessoas portadoras de transtornos mentais e redireciona o modelo assistencial em saúde mental ${ }^{17}$. Esta lei regulamenta a internação psiquiátrica, bem como suas modalidades: internação voluntária, internação involuntária e compulsória. É esclarecido no art. $6^{\circ}$ que a modalidade involuntária corresponde àquela que se dá sem o consentimento do usuário e a pedido de terceiro ${ }^{17}$, enquanto a compulsória caracteriza-se por ser determinada pela Justiça. A lei determina ainda que no caso da internação involuntária é devida a comunicação ao Ministério Público Estadual em até 72 horas, inovação que, segundo Britto ${ }^{18}$, implica a participação de um novo órgão na sistemática do tratamento desses indivíduos. Isto porque o Ministério Público passa a fiscalizar tais internações, funcionando como agente vigilante dos direitos das pessoas internadas. A Lei 10.016/01 ${ }^{17}$ também determina que o término da internação involuntária só possa ocorrer mediante requerimento escrito de familiar, responsável legal ou no caso em que o profissional ou equipe de saúde, encarregados do tratamento, assim o compreendam, bem como a pedido do Ministério Público.

Ao se analisar a legislação, percebe-se que, apesar de regulamentar e prescrever os direitos que possuem os portadores de transtornos mentais em tratamento, parece haver, ainda, clara limitação quanto à autonomia do indivíduo submetido à internação involuntária ou compulsória. Verifica-se que o internado de forma involuntária nem sempre é ouvido no momento da internação e nem ao menos participa do processo que envolve o término do tratamento ${ }^{18}$. Desse modo, pode-se argumentar pela provável violação à autonomia do indivíduo como paciente portador de transtornos mentais, fato que o coloca em situação de vulnerabilidade ante o Estado.

Ou seja, ao se comparar o cenário ora explicitado com a situação da castração medicamentosa adotada como modalidade terapêutica no bojo de uma medida de segurança, é possível concluir que o indivíduo teria, de qualquer forma, sua autonomia reduzida, sendo que no caso da internação involuntária tal fato ocorre em decorrência de uma lei, a qual passou a regulamentar e legitimar a situação em questão, o que também aconteceria quando da aplicação da castração química. Assim, partindose desse pressuposto, pode-se argumentar que na ponderação de interesses ora questionada já há posição estatal em que a autonomia do indivíduo é suprimida em face de outro(s) interesse(s).

Ainda na análise da castração hormonal como tratamento médico, sublinha-se que esse procedimento, entendido como forma de terapia, não é a única opção de tratamento, haja vista que são destacadas outras modalidades, as quais foram divididas em três categorias: 1) intervenções psicológicas, entendidas como tratamento psicológico; 2) tratamentos farmacológicos, sendo aqui inserida a castração química, além de outros procedimentos envolvendo a manipulação de drogas e, por último; 3) castração cirúrgica ${ }^{19}$. Cabe destacar, no entanto, que o tratamento hormonal é apontado como o procedimento mais eficaz entre os que compõem a categoria de tratamentos farmacológicos, além do seu caráter reversível.

A Associação Americana de Psiquiatria (American Psychiatric Association - APA) posiciona-se no sentido de que o acompanhamento psicológico deve ser constante e presente ao longo de todo o tratamento do indivíduo pedófilo, aspecto com o qual concordam as autoras do presente trabalho. A intervenção psicológica, complementar a outras medidas, pode propiciar a redução de vulnerabilidades do paciente ao favorecer $\mathrm{o}$ autoconhecimento e as estratégias de enfrentamento sobre os aspectos subjetivos, de personalidade e a própria doença (a pedofilia). Em caso de possibilidade de reincidência, avaliada pelo psiquiatra responsável, devem ser administradas drogas antidepressivas, de modo que o uso de medroxiprogesterona (medicamento usado na castração química) deve ser considerado nos seguintes cenários: permanência dos impulsos sexuais, apesar da prévia submissão a tratamentos psicológicos e farmacológicos, que não a castração química; a vítima em potencial é uma criança; as condutas relatadas incluem ideias sádicas; o comportamento de abuso sexual envolve violência física contra a vítima ${ }^{13}$. 
Segundo a APA, o uso do procedimento hormonal é percebido como último recurso, devendo ser manejado em caso de falência dos demais (acompanhamento psicológico e prescrição de antidepressivos, somados ao comportamento violento demonstrado pelo indivíduo). Ou seja, para a prescrição e aplicação da medroxiprogesterona é necessário que as terapêuticas anteriores não tenham obtido resultados satisfatórios, que o indivíduo apresente conduta sádica, agressiva e violenta, relativamente incontrolável, confirmando sem qualquer dúvida o fracasso das outras formas de terapia. A situação indica ainda o necessário comprometimento tanto do médico como do sujeito. Ademais, ressalta-se principalmente que ao se estabelecer determinados critérios para aplicação da castração medicamentosa, tem-se como resultado um procedimento menos suscetível à arbitrariedade e abuso de medicação.

\section{Experimento científico}

Considerando que a castração química ainda não é aplicada no contexto brasileiro - nem como pena nem como tratamento -, pesquisas visando avaliar a eficácia do procedimento encontram pertinência. Nessa perspectiva, a castração química enquanto objeto de experimento científico implica na consideração de todos os aspectos concernentes a uma pesquisa, tais como a ética e tudo o que tal entendimento envolve, como a autonomia do participante e o uso do termo de consentimento livre e esclarecido (TCLE).

Cumpre destacar que a castração medicamentosa como experimento científico diz respeito a pesquisa realizada com voluntários vinculados ou não ao cumprimento de uma pena privativa de liberdade. Quanto àqueles vinculados ao cumprimento de uma pena privativa de liberdade, esclarece-se que a participação em pesquisa referente ao procedimento em questão não é adotada como imposição penal, fato que torna relevante as considerações quanto à autonomia do sujeito, feitas a seguir.

Com relação às normativas que visam à proteção e promoção da autonomia dos participantes de pesquisa, há importante regulamentação que é a Resolução 466/12 do Conselho Nacional de Saúde (CNS) ${ }^{20}$, a qual, entre outras determinações, exige a utilização do TCLE, instrumento que tem como objetivo resguardar a autonomia do sujeito de pesquisa, sendo documento de natureza ética. Ocorre que, por se tratar de uma situação extremamente delicada, em que as partes envolvidas possuem interes- ses diversos, os quais muitas vezes não coincidem, é possível o surgimento de conflitos. Assim, Mello e Braz ${ }^{5}$ sustentam que apenas a aplicação do TCLE não resguarda de forma plena a autonomia do indivíduo, sendo asseverado que outras preocupações - como o estado de necessidade em que o sujeito se encontra, ao lado da falta de recursos para o tratamento de sua enfermidade, além das condições de sua saúde após se submeter a uma pesquisa - podem surgir como obstáculos para o exercício da autonomia plena do participante de uma investigação.

Cabe a consideração quanto aos obstáculos ora ressaltados, tendo em vista ser possível estabelecer uma relação entre os mesmos. Ou seja, considerando as precárias condições que a saúde pública brasileira apresenta, pode-se dizer que um indivíduo com grave condição de doença encontra-se em estado de necessidade, fato que o torna vulnerável face ao oferecimento de tratamento que eventualmente ainda está em fase de experimentação. Tal vulnerabilidade é acrescida quando o sujeito é portador de determinada patologia que não possui cura ou tratamento aplicável.

$\mathrm{O}$ estado de necessidade em que o indivíduo se encontra é algo que vem sendo considerado por diversos estudiosos, pois ao se ponderar que o TCLE é utilizado com o principal intuito de garantir uma decisão voluntária e autônoma, tal opção poderia estar viciada, vez que o sujeito em questão se encontra em situação de vulnerabilidade. Sobre o assunto, Lott ${ }^{21}$ afirma que apesar de todas as diligências, tanto nacionais como internacionais de combate a tal situação, as populações pobres continuam sendo exploradas com o fito de servir como sujeitos de pesquisa. Assim, aponta-se que tais cidadãos carecem de paridade de armas, fato que os coloca em posição de verdadeira desigualdade de poderes para se proteger das intervenções abusivas.

Tendo em vista a importância do TCLE é que se justificam todos os cuidados que o circundam, desde sua plena compreensão à acessibilidade que deve ter. Assim, no caso da castração química como experimento científico também não deve ser diferente, de modo que a autonomia e integridade dos participantes de pesquisa necessitam ser respeitadas ao máximo, principalmente ao se considerar a abrangência do procedimento em si e dos seus efeitos colaterais, os quais devem estar esclarecidos, pois são diversos os sintomas que podem vir conjuntamente com a castração medicamentosa.

No caso da pedofilia, a partir do momento em que é entendida e tratada como doença de fundo psiquiátrico, percebe-se que a falta de tratamento 
eficaz e adequado talvez venha a encaixar o indivíduo portador desse transtorno em uma das possíveis barreiras ao exercício pleno de sua autonomia, tornando-o vulnerável. Nesse sentido, a castração química como experimento científico surgiria como um dos únicos recursos para controlar tal enfermidade psiquiátrica. Portanto, devido à falta de tratamento, o indivíduo pedófilo encontra-se em especial estado de necessidade, restando concluir que essa pessoa está em situação de vulnerabilidade ante a pesquisa proposta. Desse modo, ainda que seja oferecido o TCLE da forma mais didática e acessível possível, o participante de pesquisa poderia, em sua esfera subjetiva, sentir-se vulnerável tanto por sua doença como pela falta de opções eficazes para tratá-la, submetendo-se à castração medicamentosa.

Aqui, importa salientar a noção de que a autonomia e a vulnerabilidade são elementos que se encontram em posições opostas ao indivíduo, de modo que quanto mais se promove a autonomia das pessoas, menor é a vulnerabilidade das mesmas; em paralelo, na mesma medida em que são identificadas situações nas quais a pessoa está em maior situação de vulnerabilidade, menor é a sua autonomia. Com efeito, afirma-se que a autonomia e a vulnerabilidade são conceitos ambivalentes, quando estudados no âmago dos seres humanos.

Nesta esteira, é importante registrar que a modalidade da castração hormonal como pesquisa científica foi realizada no Brasil na Faculdade de Medicina da região do $A B C$ Paulista, no Ambulatório de Transtornos de Sexualidade (ABSex). Segundo Baltieri ${ }^{13}$, professor, pesquisador e médico psiquiatra que conduziu o estudo, foi informado aos participantes que a aplicação de hormônios era subsidiária a outras terapias, entre as quais se destacavam as intervenções psicológicas e os tratamentos farmacológicos que não a administração de medicamentos hormonais. Logo, tem-se que a investigação realizada no Brasil foi fiel ao adotar a castração medicamentosa como método de controle acessório e não principal. Sobre essa pesquisa, Stetner e Rodrigues ${ }^{2}$ comentam ainda que a participação do indivíduo somente ocorria após o seu consentimento informado e livre, fato que demonstra a observância dos preceitos éticos para sua realização, tal como reza a regulamentação brasileira na pesquisa com seres humanos. Destaca-se que, de acordo com parecer da Comissão de Constituição, Justiça e Cidadania do Senado Federal ${ }^{22}$, o número de participantes voluntários do referido estudo chegou a 30 pessoas.

Frisa-se que a pesquisa em questão sofreu descontinuidade, e que resultados sobre os 30 participantes não foram divulgados. No entanto, foi relatado por Baltieri ${ }^{13}$ o estudo de caso de um dos participantes da pesquisa (Sr. Z), o qual foi submetido a tratamento para controle de pedofilia, de modo que primeiro teve acompanhamento psicológico, seguido de terapia farmacológica consistente na manipulação de drogas antidepressivas, sendo que tais modalidades de tratamento não obtiveram resultado. Em decorrência, foi informado acerca do tratamento hormonal e concordou em submeter-se ao procedimento. Iniciada a administração da medroxiprogesterona, o indivíduo relatou total ausência de fantasias sexuais que envolvessem crianças. Entretanto, o autor afirmou que, com a exposição da mídia sobre a pesquisa que estava sendo efetuada, houve na época diversas críticas negativas e o sujeito de pesquisa passou a ter o receio de ser identificado de alguma forma, fato que o fez parar com o tratamento e abandonar o experimento.

De qualquer forma, os dados ora apresentados são de importância para algum entendimento, tanto da pedofilia como da castração química, pois os resultados acerca de um sujeito de pesquisa sugerem que parece possível o controle da doença. Sua descontinuidade, no entanto, limita as conclusões acerca das consequências da aplicação desse procedimento a médio ou longo prazo.

\section{Considerações finais}

Tendo em vista a escassez de trabalhos acadêmicos sobre o assunto, bem como o fato de que uma pesquisa científica sobre a castração química foi descontinuada no Brasil, considera-se que o presente estudo teve o mérito de ampliar a compreensão do tratamento hormonal para pedófilos. O tema foi desenvolvido por meio do levantamento e análise de artigos científicos, documentos legais e oficiais sobre castração química, obras sobre pedofilia e as vertentes bioéticas aplicáveis, além da bibliografia referente à sua abordagem enquanto pena, tratamento médico e experimento científico.

A eventual aplicação da castração química enquanto pena levanta obstáculos que devem ser solucionados para que tal modalidade seja eticamente aceitável, entre os quais se destacam: o entendimento do pedófilo como indivíduo portador de uma doença e a aplicação da castração medicamentosa como medida de segurança.

Com relação à acepção da castração química como tratamento médico, foi ressaltado o direito à saúde, o qual implica em dever do Estado prover a 
terapia adequada para cada patologia. Aqui, esbarra-se novamente na aplicação do procedimento enquanto medida de segurança, pois, conforme analisado, apesar de ser doença a pedofilia não deixa de ser um crime. Também foi sobrelevada a questão da compulsoriedade da castração medicamentosa enquanto tratamento médico, sendo este um conflito ético próprio dessa modalidade.

No âmbito da pesquisa científica os dilemas éticos residem no fato de que a pedofilia não possui cura, fato que torna o indivíduo pedófilo vulnerável ao se estabelecer como voluntário para tal experimento, pois esta seria sua única opção de terapia.

Desta feita, aduz-se que o presente trabalho evidenciou os conflitos éticos ora elencados, identificando-os e discutindo-os. Assim, afirma-se que muito embora tais dilemas não tenham sido solucionados - e provavelmente nunca o serão - seu debate enriqueceu as noções sobre o tema. Por se tratar de assunto extremamente delicado, a apresentação das possíveis modalidades de adoção da castração química contribuiu para seu melhor entendimento, o que enseja muitos desafios e controvérsias.

Conclui-se que as três acepções não se excluem: a castração química como pena, tratamento médico e experimento científico representa arquétipos que se encontram intrinsecamente ligados, apesar de cada um possuir conotações éticas próprias. Há indícios de que o país vem se preparando para progredir no tocante à forma de lidar com a pedofilia enquanto crime e doença. Para isso, faz-se necessária a apresentação eficaz do tema mediante a difusão ao público brasileiro de premissas básicas para melhor discussão do assunto. Entre tais premissas, inclui-se a noção de que a pedofilia é uma doença que merece tratamento adequado. É nesse sentido que se conclui pelo entendimento de que o tratamento hormonal consistente da castração química é um procedimento pertinente para abordar a questão.

Trabalho realizado no âmbito do programa de pós-graduação em Bioética da Universidade de Brasilia (UnB).

\section{Referências}

1. Organização Mundial da Saúde. CID-10: classificação estatística internacional de doenças e problemas relacionados à saúde. [Internet]. 2010 (acesso 23 ago. 2013). Disponível: http:// trigramas.bireme. $\mathrm{br} / \mathrm{cgi}$-bin $/ \mathrm{mx} / \mathrm{cgi}=\% 401$ ?collection $=C$ ID10p\&lang=p\&minsim=0.30\&maxrel $=1$ 0\&text=Pedofilia

2. Stetner CN, Rodrigues GM. Castração química: limites e possibilidades à adoção como penalidade para pedofilia. Rev Gestão \& Políticas Públicas. 2011(acesso 2 set. 2011);1(1). Disponível: http:// each.uspnet.usp.br/rgpp/index.php/rgpp/article/view/13

3. Ponteli NN, Sanches Jr CA. Notas para uma análise sociológica da castração química. Rev Levs/ Unesp. 2010 (acesso 26 ago. 2011);(5). Disponível: http://www2.marilia.unesp.br/revistas/index. $\mathrm{php} /$ levs/article/viewFile/1111/999

4. Scott CL, Holmberg T. Castration of sex offenders: prisoners' rights versus public safety. J Am Acad Psychiatry Law. 2003 (acesso 6 out. 2011);31(4):502-9. Disponível: http://www.jaapl.org/ content/31/4/502.full.pdf

5. Mello DG, Braz M. Vulnerabilidade, autonomia e ética em pesquisa. Rev Brasileira de Bioética. 2008;4(1-2):49-68.

6. Ferreira PPC. A castração química como alternativa no combate à pedofilia: algumas palavras acerca do Projeto de Lei $n^{\circ}$ 552/2007 e o modelo político-criminal emergencial. Ciências Sociais Aplicadas em Revista. 2009 (acesso 9 out. 2011);9(17). Disponível: http://e-revista.unioeste.br/ index.php/csaemrevista/search/authors/view?firstName=Pedro\&middleName=Paulo\%20da\%20 Cunha\&lastName=Ferreira\&affiliation $=$ UEM

7. Brasil. Câmara dos Deputados. Projeto de Lei $n^{\circ} 4.399$, de 27 de novembro de 2008. Acresce 0 artigo 223-A ao Decreto-lei $n^{\circ} 2.848$, de 7 de dezembro de 1940. Código Penal, para permitir a castração química na recuperação de pedófilos reincidentes. [Internet]. 2008 (acesso 19 nov. 2012). Disponível: http://www.camara.gov.br/proposicoesWeb/fichadetramitacao?idProposicao=418075

8. Brasil. Senado Federal. Projeto de Lei do Senado $n^{\circ} 552$, de 18 de setembro de 2007. Acrescenta o art. 216-B ao Decreto-lei n 2.848, de 7 de dezembro de 1940. Código Penal, para cominar a pena de castração química nas hipóteses em que o autor dos crimes tipificados nos arts. 213, 214, 218 e 224 for considerado pedófilo, conforme o Código Internacional de Doenças. [Internet]. 2007 (acesso 22 out. 2011). Disponível: http://www.senado.gov.br/atividade/materia/detalhes. asp?p_cod_mate $=82490$

9. Brasil. Senado Federal. Projeto de Lei do Senado $n^{\circ} 282$, de 24 de maio de 2011. Altera o Código Penal, para prever medida de segurança de tratamento químico-hormonal aos condenados por pedofilia. [Internet]. 2011 (acesso 22 nov. 2012). Disponível: http://www.senado.gov.br/ atividade/materia/detalhes.asp?p_cod_mate $=100380$ 
10. Serafim AP, Saffi F, Rigonatti SP, Casoy I, Barros DM. Perfil psicológico e comportamental de agressores sexuais de crianças: revisão. [Internet]. Rev Psiquiatr Clín. 2009 (acesso 20 nov. 2011);36(3):101-11. Disponível: http://www.hcnet.usp.br/ipq/revista/vol36/n3/105.htm

11. Brasil. Decreto-lei n 2.848, de 7 de dezembro de 1940. Código Penal. [Internet]. 1940 (acesso 2 dez. 2011). Disponível: http://www.planalto.gov.br/ccivil_03/decreto-lei/del2848.htm

12. Peres MFT, Filho AN. A doença mental no direito penal brasileiro: inimputabilidade, irresponsabilidades, periculosidade e medida de segurança. [Internet]. Hist Ciênc Saúde Manguinhos. 2002 (acesso 16 set. 2012);9(2):335-57. Disponível: http://egov.ufsc.br/portal/ sites/default/files/anexos/30839-33197-1-PB.pdf

13. Baltieri DA, Andrade AG. Treatment of paraphilic sexual offenders in Brazil: issues and controversies. Int. J Forensic Mental Health. 2009;8(3):218-23.

14. Brasil. Constituição da República Federativa do Brasil. Brasília: Senado Federal; 1988.

15. Sarlet IW. Algumas considerações em torno do conteúdo, eficácia e efetividade do direito à saúde na Constituição de 1988. Rere. 2007 (acesso 9 jul. 2013);(11). Disponível: http://egov.ufsc.br/ portal/sites/default/files/anexos/31953-37383-1-PB.pdf

16. Hachet A. Agressores sexuais: é possível um tratamento psicanalítico sob prescrição judicial? Agora. 2005 (acesso 7 nov. 2011);8(1):47-62. Disponível: http://www.scielo.br/pdf/agora/v8n1/ v8n1a04.pdf

17. Brasil. Lei $n^{\circ} 10.216$, de 6 de abril de 2001. Dispõe sobre a proteção e os direitos das pessoas portadoras de transtornos mentais e redireciona o modelo assistencial em saúde mental. [Internet]. 2001 (acesso 3 ago. 2013). Disponível: http://www.planalto.gov.br/ccivil_03/leis/ leis_2001/l10216.htm

18. Britto RC. A internação psiquiátrica e a Lei no 10.216/01: reflexões acerca da garantia de proteção aos direitos da pessoa com transtorno mental. [dissertação]. Rio de Janeiro: Fundação Oswaldo Cruz; 2004 (acesso 5 ago. 2013). Disponível: http://thesis.icict.fiocruz.br/pdf/brittorcm.pdf

19. Ribeiro RB, Cordeiro Q. Sex offenders: risk assessment, risk factors and treatment. [Internet]. Arq Med Hosp Fac Ciênc Méd Santa Casa de São Paulo. 2012 (acesso 22 jul. 2013);57(2):74-80. Disponível: http://www.fcmscsp.edu.br/files/05-AR12.pdf

20. Conselho Nacional de Saúde. Resolução $n^{\circ} 466$, de 12 de dezembro de 2012. Aprovar as diretrizes e normas regulamentadoras de pesquisas envolvendo seres humanos. [Internet]. 2012 (acesso 6 set. 2013). Disponível: http://conselho.saude.gov.br/resolucoes/2012/Reso466.pdf

21. Lott J. Populações especiais e vulneráveis. [Internet]. (acesso 24 jul. 2013). Disponível: http:// www.udo-schuklenk.org/files/modulo3.pdf

22. Brasil. Senado Federal. Parecer da Comissão de Constituição, Justiça e Cidadania sobre o Projeto de Lei do Senado n 552, de 2007 (acesso 27 nov. 2011). Disponível: http://legis.senado.leg.br/ mateweb/arquivos/mate-pdf/56869

\section{Participação dos autores}

Thais M. de S. Maia idealizou e redigiu o artigo. Eliane M. F. Seidl contribuiu na redação e revisou o artigo.

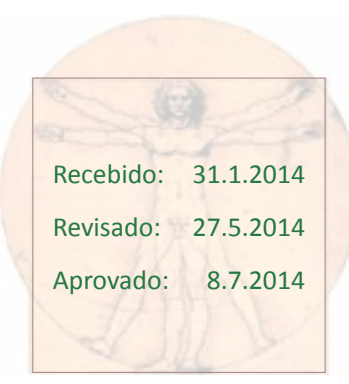

